\title{
Desafíos del bicentenario
}

\author{
Milagros Varela Gómez \\ Universidad Antonio Ruiz de Montoya, Lima, Perú \\ ORCID: https://orcid.org/0000-0002-1606-5488
}

Correspondencia: martha.varela@uarm.pe

\section{Resumen}

En este artículo, realizo una reflexión en torno a las raíces de los desafíos que enfrenta el Perú al haber cumplido doscientos años de vida republicana. Para este propósito, propongo un análisis de los antecedentes de las independencias sudamericanas, vinculando el sentido económico y político de las dos corrientes libertadoras que llegaron al Perú para concluir, finalmente, que estos proyectos tuvieron limitaciones que explican la identidad de nuestra actual república.

Palabras claves: bicentenario, expediciones libertadoras, corrupción, Perú republicano.

\begin{abstract}
In this article I reflect on the roots of the challenges that Peru faces, having completed two hundred years of republican life. For this purpose, I propose an analysis of the antecedents of South American independences, linking the economic and political sense of the two liberating currents that arrived in Peru. Finally, to conclude that these projects had limitations that explain the identity of our current republic.
\end{abstract}

Keywords: bicentennial, expedition liberated, corruption, Republican Peru.

\section{Introducción}

En este ensayo, trato de buscar en la historia las causas de los desafíos que enfrenta el Perú al cumplirse el bicentenario de nuestra independencia política de España. Esos desafíos consisten en superar las desigualdades 
económicas y sociales que nos dividen, eliminar la discriminación que nos separa y acabar con la corrupción que nos agobia a los peruanos. Construir una república basada en ciudadanos libres, con diferencias culturales respetadas y derechos iguales, sigue siendo un objetivo que todavía no hemos alcanzado, a pesar de que ya tenemos 200 años de vida republicana contados desde 1821 .

Para explicar las causas que propongo tomar en cuenta, hago un resumen de los antecedentes de la independencia de las colonias españolas en Sudamérica, sintetizo la prolongada guerra entre España, Francia e Inglaterra y sus consecuencias en la independencia, explico el sentido económico y político de las dos corrientes libertadoras que llegaron al Perú, y señalo las limitaciones que tuvo el proyecto libertador, limitaciones que explican las características de nuestra república actual.

\section{Desarrollo}

\section{El Perú, la última fortaleza colonial de Sudamérica}

La Declaración pronunciada por José de San Martín en Lima el 28 de julio de 1821 y la capitulación firmada por el general José de La Serna en Ayacucho en 1824 fueron la culminación de la lucha por la independencia política de las colonias españolas en Sudamérica. El Perú fue la última fortaleza espańola en ser tomada por los independentistas que llegaron desde la capitanía de Venezuela en la Nueva Granada, y desde las provincias coloniales del Virreinato del Río de la Plata y la Capitanía de Chile; estas intervenciones externas al Perú contaron con la ayuda de los montoneros y los guerrilleros que combatieron contra la corona peninsular aquí, en el corazón del virreinato peruano. Fueron los acontecimientos culminantes del capítulo que cubre los años que están entre las juntas de gobierno de 1810 y la batalla de Ayacucho de 1824 .

\section{La guerra interminable}

Ahora alejémonos un poco en el tiempo. Considerada en plazos largos, la independencia de las colonias españolas es parte de la guerra entre los imperios español e inglés, que incluye la emergencia de la potencia 
francesa en el mundo globalizado de la época, un prolongado conflicto armado que empezó en el siglo XVI entre Felipe II e Isabel I Tudor y se mantuvo de manera intermitente con distintas incidencias durante tres siglos hasta finales del XVIII. Fueron las siguientes guerras concatenadas: la angloespañola de 1585 a 1604 entre Isabel I y Felipe II; la que desató Oliverio Cromwell entre 1655 y 1660, el revolucionario puritano que también atacó a España; la de 1739-1768, en que los ingleses quisieron hacerse del imperio espańol; la lucha armada por la independencia de las trece colonias 1775-1783; y la guerra angloespańola de 1779-1783. Inglaterra, Francia y España disputaban por los ricos territorios americanos.

Apenas conquistada Granada y devastada la América indígena, Castilla sufrió una nueva colonización: la que venía del centro de Europa a través de Felipe de Habsburgo el Hermoso y su hijo Carlos v, al punto que se puede sostener que, durante gran parte de los 300 ańos del denominado imperio español y americano, en realidad las cortes de Valladolid y Madrid estaban subordinadas a los Habsburgo por la vía de las relaciones familiares entre Carlos y su hermano Fernando I, residente en Viena, archiduque de Austria, rey de Romanos, rey de Bohemia y Hungría, y Maximiliano, el abuelo de ambos; y a la banca alemana y holandesa por los préstamos y actividades económicas de la monarquía.

Y cuando, luego de la guerra de sucesión de finales del siglo XVIII, los Borbones reemplazaron a los Austrias en la península, todas las provincias americanas del imperio espańol se convirtieron, junto con España, en un apéndice de los Borbones.

Hay que tomar en cuenta este complicado juego de ajedrez de las casas reales de la época durante los siglos XVI, XVII y XVIII, para entender el sentido, la trascendencia y también las limitaciones que tuvo la Declaración de Independencia pronunciada por San Martín el 28 de julio de 1821 sin las contradicciones y las guerras entre Inglaterra, Francia y España; si Inglaterra no hubiese sido derrotada por la coalición entre Washington, los colonos ingleses y las potencias europeas; si no se hubiese producido la revolución en Francia y Napoleón Bonaparte no hubiese invadido la península; si Inglaterra no hubiese querido vengarse de los Borbones financiando a los masones sudamericanos, todavía seguiríamos siendo una provincia del imperio español, puesto 
que la lealtad a la corona pesó siempre más que la rebelión en la Lima colonial. Cabe esta ucronía para explicar lo que somos, aunque los historiadores peruanos han insistido siempre en afirmar la importancia de la presencia local en el proceso de la independencia.

\section{Los vencedores}

Toda esta historia empezó en 1492, con la conquista de Granada por los reyes católicos, la expulsión de los judíos de la península ibérica y los viajes de Cristóbal Colón. La llegada de Colón al continente americano fue el comienzo de una violenta y premeditada agresión, motivada por la codicia, contra una cultura que tenía 15000 años de antigüedad. No hubo un choque, hubo un aplastamiento. Los virus portados inconscientemente por los europeos precedieron a Pizarro ${ }^{1}$ y causaron una mortandad generalizada que facilitó la conquista, el mundo microbiano occidental aniquiló al americano. Los perros de los saqueadores, entrenados para descuartizar ${ }^{2}$, destrozaron los cuerpos de

1 "La Epidemiología Española de J. Villalba (1803) indica que había bubas en Aragón desde el año 591, viruela en Andalucía desde el 714 introducida por los árabes, lepra en Asturias en 923, malaria en Valencia ya en 1324 y peste bubónica también en Valencia y el resto de las regiones espańolas desde 1348 [...] La Medicina castellana atribuida a Samuel ben Waqar, nacido en Toledo y médico de Femando IV y Alfonso XI, en una de cuyas versiones en castellano, fechada en 1414, dice que las enfermedades más frecuentes de Castilla eran «las calenturas pútridas, sarampión, viruelas, tercianas, catarros, destilaciones, esputos de sangre, tisis, asmas, dolores de cólicos nefríticos y afectos espasmódicos» (Guerra, 1988, pp. 43-51).

2 "Los perros de los conquistadores eran alanos de raza, un mestizaje entre dogos y mastines... Con su feroz presencia, representaban la viva manifestación de una insoportable forma de terror casi demoníaca. Siempre iban en primera línea acompañando a los ballesteros y delante de los arcabuceros, y por supuesto, cuando actuaban juntamente con la caballería, el pánico que causaban en las filas adversarias era extremo. Estos animales iban protegidos con sendas tiras de cuero en ambos lomos y unas potentes protecciones de fieltro que se extendían desde la cruz del tren delantero hasta el nacimiento del rabo, de tal manera que parecían acorazados contra cualquier contingencia. Si a esto le añadimos los ostentosos collares dentados y el durísimo entrenamiento al que los sometían sus amos - que cobraban una soldada aparte por perro-, estaríamos hablando de un arma casi apocalíptica" (Van den Brule, 2016). 
los indígenas. Miles de obras de arte fueron fundidas para convertirlas en lingotes de oro y plata. Los palacios fueron desmantelados, destruidas sus coberturas de metales preciosos y robados sus coloridos tapices. Las religiones a las que los invasores llamaron idolatrías fueron extirpadas, aunque se mantuvieron en el fondo de las conciencias y las conductas. Las terrazas andinas y los acueductos fueron abandonados. Fue introducida la esclavitud, una institución antihumana que no existía en estas tierras. El ganado bovino, ovino y caprino expulsó a los camélidos de los mejores pastos, el trigo desplazó a los granos andinos.

\section{La contribución americana}

La tecnología europea llegó por la vía de las armas y el genocidio. A cambio de ello, Europa se benefició con la papa y el maíz que salvaron del hambre a poblaciones enteras, el cacao y el tabaco que cambiaron la vida de la gente y con la visión de una sociedad diferente que inspiró las utopías que sirvieron de base para los proyectos revolucionarios y las democracias actuales, y determinaron la historia global hasta estos tiempos. Como afirma Germán Arciniegas:

[...] esa utopía fue a la vez protesta e ilusión, protesta por el abuso e ilusión por lo que se podía construir [...] Para los filósofos hubo en América desde Vespucio una tierra firme sobre la cual pudieron construir repúblicas ideales. El anuncio de América continental produce el cambio más profundo en la historia del pensamiento de occidente. (2005, p. 53)

Las instituciones indígenas estuvieron en la base de la organización de la democracia norteamericana. El descubrimiento de América motivó las tesis de Copérnico y Galileo, pero fue un cataclismo, un choque, un violento intercambio. También, las consecuencias las estamos pagando todavía. 


\section{Secuencia libertadora}

A partir de la guerra entre España e Inglaterra que durante el siglo XviII comprometió también de manera protagónica a Francia, se produjo la secuencia de acontecimientos que culminó en lo que conocemos como un país llamado Perú, que es políticamente independiente, aunque no lo sea desde el punto de vista mental y económico.

Espańa y Francia ayudaron a George Washington en la guerra libertadora que culminó en 1776, porque querían perjudicar a Inglaterra. Desde La Habana y la Florida española, Francisco de Miranda y el adolescente conde de Saint Simon, el primero oficial español y el segundo francés, cumplieron la misión imperial de enviar dinero y armas a las colonias inglesas rebeldes. Desde Haití, los franceses enviaron soldados mulatos que combatieron al lado de Washington. Finalmente, España y Francia lograron su objetivo: dejar a Inglaterra sin sus colonias principales de la época, pero quedaron empobrecidas y débiles. La guerra contra Inglaterra creó en Francia la crisis económica que causó el trágico fin de Luis Xvi y su corte cuando el tercer estado y los hambrientos sans culottes se sublevaron contra la aristocracia en París.

Francisco de Miranda paseó las cortes de Europa y planificó el futuro de una América española libre desde una visión integradora de ciudadanía universal, con el apoyo de Inglaterra. Los mulatos esclavos que hicieron la guerra al lado de Washington enviados por los franceses desencadenaron a su regreso a las Antillas la primera revolución triunfante de esclavos en el mundo, que elevó al poder a Toussaint de L'Overture y abolió la esclavitud (Madieu, 1989).

Los nacidos en el Perú no fuimos solo receptores, sino que formamos parte de ese proceso como actores. Una línea de continuidad lleva de la guerra norteamericana a la revolución de Túpac Amaru, de la Revolución francesa a la de Haití, al periodo napoleónico, la ocupación de España por los franceses, la prisión de Fernando VII, las juntas de gobierno y las guerras americanas de independencia. La revolución también salió de aquí con los alzados andinos y regresó con los expedicionistas ingleses, argentinos y chilenos. 
En Sudamérica, cual brazos de tenaza, dos corrientes, la del sur y la del norte, terminaron en Lima en el periodo 1820-1824. La corriente del sur, que culminó con la Expedición Libertadora de San Martín y Cochrane y la Declaración de independencia de 1821, no se originó en la costera Buenos Aires, sino en la andina Chuquisaca. Fue Chuquisaca, el centro cultural altiplánico, donde nació y estudió José Bernardo de Monteagudo, el brazo organizador y político de San Martín. Fue Córdoba, la ciudad docta, entre Salta y Buenos Aires, entre las estribaciones andinas y la influencia porteña, el otro centro cultural, donde estudió Manuel Belgrano. Chuquisaca, Salta y Tucumán formaron parte del espacio de influencia altiplánico, cuyo rico centro económico era Potosí, de donde procedieron los militantes revolucionarios de la Junta de Buenos Aires de 1810, opuestos a los moderados comerciantes proingleses del puerto. En Tucumán, fue donde se desarrolló el Congreso que decidió la independencia de las provincias del Río de la Plata en 1816. Se puede afirmar entonces que la corriente sureña que arribó a Paracas no tuvo un origen porteño, sino andino; no vino del mar Atlántico, sino de las estribaciones de los Andes, gracias al gran rodeo que el genio militar de San Martín concibió mediante el paso de la cordillera para atacar Lima por el sur. Y, además, esta corriente sureńa estuvo encadenada a la influencia y el recuerdo de la revolución de los Túpac Amaru. José Gabriel, el último de los Túpac Amaru, sobreviviente luego de cuarenta ańos de cautiverio en Ceuta, África, ya anciano, fue recibido con honores en Tucumán; y Manuel Belgrano presentó, probablemente en su presencia, su Plan Inca, por el cual las provincias de Sudamérica debían unirse en un solo gran país heredero del Tawantinsuyu bajo el gobierno de un monarca cusqueño (Fraga, 2016).

La corriente norteńa procedió de Caracas. A diferencia de Lima y el Perú, cuyos habitantes españoles eran descendientes de los conquistadores o funcionarios coloniales enviados por Madrid o Valladolid y, por tanto, se debían a la metrópoli, buena parte de Venezuela fue poblada por migrantes vascos o canarios que no llegaron buscando oro, sino para convertirse en colonos y comerciantes importadores, o cultivadores de café y cacao. Mientras en Lima el 
Tribunal del Consulado era la entidad económica más importante, la Real Compañía Guipuzcoana ${ }^{3}$ lo era en Caracas. Las islas Canarias fueron pobladas por judíos que huían de España. Sus descendientes arribaron a Venezuela. Sin embargo, no eran tan diferentes.

Además, había grandes fortunas de los criollos. Los padres de Bolívar eran dueños de no menos de doce casas en Caracas y el puerto de La Guaira, una hacienda en expansión en el valle de Aragua, una mina de cobre, cultivos de caña de azúcar, huertos frutales, una destilería de ron, un negocio textil, plantaciones de cacao y añil, así como haciendas de ganado y cientos de esclavos (Arana, 2020).

No teniendo un puerto como el Callao, que era controlado por el ejército colonial, situados en una lejana Capitanía sin mayor importancia si se la compara con la rica Potosí o la virreinal Lima, fuera de la principal ruta de navegación que en aquella época cursaba el Callao, Panamá, Cartagena, La Habana y Sevilla llevando tesoros y trayendo provisiones, los venezolanos hicieron, desde los lejanos lugares incontrolados de la colonia, frecuente relación con los comerciantes ingleses. Tenían un espíritu más moderno e independiente y una visión distinta de España, del mundo y de la economía global. No era esta una situación general en Venezuela, puesto que también estaban los llamados mantuanos que se consideraban blancos y españoles auténticos, diferentes de los blancos de orilla o gentes de origen sospechoso. Simón Rodríguez, Simón Bolívar, Francisco de Miranda y otros grandes personajes son consecuencia de este proceso contradictorio. La relación de Miranda y Bolívar con Inglaterra, sobre todo la de Miranda, fue más estrecha y frecuente que la de Buenos Aires, porque, en el caso de la Junta del Sur, la mayor relación con los ingleses estaba en manos de comerciantes o hijos de comerciantes porteños, como Pueyrredón y Rivadavia, que optaban por una relación práctica, beneficiosa para ellos, pero finalmente neocolonial, con Inglaterra. Al final, dejaron sin apoyo a San Martín y nunca le permitieron retornar a su patria de origen.

3 La Real Compañía Guipuzcoana, constituida por ricos comerciantes vascos, monopolizaba las transacciones comerciales entre Espańa y la Capitanía de Venezuela. 
Si en el caso de San Martín teníamos como respaldo económico y político los comerciantes de Buenos Aires y en el de Bolívar los productores de Caracas, en el caso de Lima no existía ningún grupo relacionado con Inglaterra ni partidario de la independencia. De ahí procede también nuestra debilidad inicial. En vez de ello, el virrey Abascal basaba la estabilidad de la capital del Virreinato en su relación orgánica con los comerciantes del Tribunal del Consulado de Lima que disfrutaban del comercio monopólico del Callao, entrada obligada para todo el Virreinato. Lima tenía una conveniente y también leal relación con la metrópoli, esa relación era parte esencial de su vida; y la independencia era, para los miembros del Tribunal, un obstáculo y un peligro.

La estadía de San Martín en Lima fue breve (solamente los años 1821 y 1822), perdió el apoyo de Buenos Aires y no tenía modo de conseguir más préstamos de Inglaterra. La de Bolívar cubrió desde el 23 hasta 1826, adulado, pero también odiado por las familias limeńas. Más allá de los discursos, los saraos y los homenajes, San Martín y Bolívar eran, finalmente, extraños a nuestro país. Sus ideas no dejaron huella. Los planes educativos lancasterianos de San Martín fueron abandonados ${ }^{4}$. La Constitución y la presidencia vitalicia planteadas por Bolívar fueron abolidas. Y al retirarse los comerciantes monopólicos del Tribunal del Consulado después de la batalla de Ayacucho con todas las garantías que la Capitulación les concedió, quedó el Perú convertido súbitamente en república sin haberlo pedido nunca. Se produjo no solo un vacío de poder político, sino también de poder económico, vacío que sería llenado primero con los iniciales préstamos ingleses -en realidad, deudas - y mucho después, ya en los cuarenta, con el guano de islas. Eso determinó, con el paso de los años y la acción decidida de Diego Portales, el predominio de Valparaíso sobre el Callao, debido a la mayor relación de los chilenos con Inglaterra, dado que, al cruzar el

4 Joseph Lancaster. Educador inglés que creó un método de enseñanza mutua basado en la transmisión de conocimientos por grupos. Convertidos en monitores, unos alumnos instruían a otros alumnos. James Thompson fue invitado por San Martín para iniciar su método en el Perú y después lo aplicó en Caracas y el Río de la Plata. Joseph Lancaster y Jeremy Bentham fueron los intelectuales ingleses más importantes de su tiempo. 
estrecho de Magallanes por el sur, Valparaíso era el puerto más cercano para los viajes desde Europa. A eso se añadió la eliminación de la Confederación Perú-Boliviana después de la invasión chilena en 1834. Entonces, se produjo la paradoja de una república con una historia milenaria indígena no aceptada a la vez que un origen inmediato de extrema debilidad cultural, política y económica.

\section{La resistencia indigena}

La independencia política del Perú en 1821 fue también la consecuencia de una larga resistencia de los pueblos indígenas desde el arribo de los europeos a estas tierras, resistencia que estuvo compuesta de rebeliones, del porfiado mantenimiento de las costumbres ancestrales de los vencidos contra la voluntad de los conquistadores, el sincretismo religioso de los evangelizados y múltiples violaciones de las rígidas normas coloniales de separación de sangres por parte de invasores e invadidos.

Esa silenciosa y a veces abierta rebeldía de siglos tiene muchos episodios que, como la punta de un iceberg, aparecen en la historia, ocultando amplísimas bases constituidas por sucesos que ahora nos son desconocidos. Los hechos más notables son la sublevación de las familias reales locales contra Pizarro y Almagro cuando estos llegaron al Cusco, la fuga de estas familias hacia los valles subtropicales del Antisuyo, la rebelión de Manco Inca, el periodo de treinta años de los incas rebeldes de Vilcabamba que culmina con la captura y el sacrificio de Túpac Amaru I, la retirada de miles de familias quechuas, pocras y chancas siguiendo las multitudinarias peregrinaciones del Taki Onqoy ${ }^{5}$, las múltiples sublevaciones locales que no han sido registradas por la historia; y la culminación de todo ese proceso con las sublevaciones del nunca derrotado Juan Santos Atahualpa y el sacrificio de Túpac Katari y Túpac Amaru II en 1780. El mundo colonial, considerado desde hoy parece quieto, pero en realidad fue activo y turbulento.

5 "El Taki Onqoy lo que hizo, al menos ideológicamente, fue arrebatarle el poder y el protagonismo al dios cristiano para otorgárselo a las huacas, es decir, se trata de un ataque directo a los principios y dogmas de la Iglesia del momento ya que estaría negando la omnipotencia de Dios” (Barrera Alarcón, 2015, p. 20). 


\section{La discriminación}

A lo largo de 300 años, esta cultura nativa fue sometida, despreciada, ignorada, al tiempo que sus sabios depositarios, sacerdotes, astrónomos, quipu camayoc (lectores de quipus) y otros funcionarios callaron, fueron asesinados, murieron sin trasmitir sus conocimientos o fueron perseguidos. Esto significó la pérdida para el mundo de un inmenso bagaje cultural y una antigua sabiduría que nunca pudo ser recuperada.

Los pueblos de la base social de aquella confederación de naciones fueron concentrados en reducciones, las élites indígenas fueron subordinadas al imperio español y este quedó a su vez en situación de dependencia de la sociedad moderna del siglo xvi, cuyo epicentro ya no era la península ibérica, sino la Europa continental. Los habitantes americanos de la base imperial se habituaron a la obediencia al dominador, o tuvieron que recurrir a la simulación para sobrevivir. Despreciada o extirpada su cultura, fue cortada la comunicación entre generaciones. Asesinadas, silenciadas o sometidas, las élites locales perdieron la mayor parte de su bagaje cultural.

La promoción de generales y militares que dirigió la lucha por la independencia a partir de 1810 en Sudamérica se formó en las filas del ejército colonial español. Francisco de Miranda combatió contra los ingleses en La Florida y Jamaica. San Martín luchó desde los doce años en el ejército español y combatió a moros, franceses e ingleses. Francisco de Miranda fue hijo de un judío converso, acusado de ser guanche, es decir, indígena de Canarias, y mulato (Aguilar Meza, 2021). San Martín fue hijo de un funcionario colonial español y, probablemente, de una mujer guaraní.

Muchos oficiales que sucedieron a los libertadores fueron también, como los peruanos La Mar y Gamarra, oficiales de mediana y alta graduación en el ejército español. Servir en el ejército era una de las formas de ser aceptado y de ascender en la escala social del mundo colonial. Para algunos personajes excepcionales, como Miranda y San Martín, fue la ruta hacia las ideas independentistas. Para otros, eso significaba también sentirse español, incorporar a la propia conciencia 
los intereses de la metrópoli, mirar por encima a las clases bajas y a la gran base indígena de la colonia. Como consecuencia de este fenómeno de falsa conciencia, puesto que muchos de esos militares mestizos se sentían españoles, las que serían direcciones políticas de las repúblicas criollas no procedieron del mundo indígena, sino de uno de los extremos terminales del estado opresor: las fuerzas armadas de la época. No vieron a los indígenas como ciudadanos, sino como súbditos indeseables pero imprescindibles, porque necesitaban de ellos para que fueran sus soldados en las guerras civiles; o como trabajadores en la agricultura, porque los caudillos se convirtieron en terratenientes cuando se quedaron con las tierras de los españoles que retornaron a la península. Eso identificó a las nuevas direcciones políticas de las repúblicas criollas más con el mundo español que con el mundo indígena: tenían que asumir el rol de nuevos conquistadores en su propio país. La entidad nacional no acabó de soldar sus distintas piezas.

\section{La corrupción}

¿Y la corrupción? Desde sus orígenes, las casas reales europeas estuvieron cruzadas de intrigas, matrimonios por interés, asesinatos, incestos, matanzas masivas y muchos otros crímenes u otras conductas inadecuadas. De ellos proceden indirectamente nuestras familias dirigentes y directamente nuestro sistema y forma de vida. Todo tipo de crímenes forma parte normal de la historia y los consideramos como hechos característicos e inevitables de la naturaleza humana que no merecen un juicio valorativo, puesto que cualquier juzgamiento no tendría ninguna consecuencia efectiva en indemnización a las víctimas o castigo a los culpables. Los consideramos como parte de una época que no puede ser juzgada con los valores y las creencias de los tiempos actuales, aunque esto no es necesariamente cierto.

La corrupción forma parte de esta manera de ser. El esclavismo abierto y de desaforado de Colón, las capitulaciones o los arreglos de aventureros buscadores de fortuna y títulos de nobleza con reyes necesitados de oro, que eran, en realidad, contratos para el saqueo de los pueblos, y la costumbre reiterada de dar u obtener prebendas como 
parte del ejercicio público no es nada nuevo. Jorge Juan y Antonio de Ulloa (p. 144) pasaron a la historia por sus Noticias secretas, una detenida descripción de cómo era la navegación en los barcos irresponsablemente sobrecargados en comparación con las "combis" de hoy, el abandono de la marina, el descuido de la marinería, el desprecio del peligro, la falta de mantenimiento de los buques, la falta de educación de los pilotos, el fraude en el comercio, $y$

la miserable, infeliz y desventurada suerte de una nación que sin otro delito que la simplicidad ni más motivo que el de una ignorancia natural, han venido a ser esclavos y de una esclavitud tan opresiva que comparadamente pueden llamarse dichosos aquellos africanos a quienes la fuerza y razón de colonias han condenado a la opresión servil. (Jorge Juan y Antonio de Ulloa, p. 252)

La existencia de palabras quechuas, como sua, huaccho, yana, también significa que el robo, la pobreza y la orfandad no eran problemas ajenos a los tiempos precolombinos.

La modernidad, en el sentido de separar los bienes públicos de los privados, nunca penetró de verdad totalmente en el ejercicio de la administración de los estados independientes sudamericanos y la corrupción es un mal global en los tiempos que corren.

La autorización de San Martín, Unanue y Monteagudo a James Paroissien y Juan García del Río, los enviados extraordinarios y ministros plenipotenciarios que iban con la misión de obtener "de cualquier gobierno o cualquier individuo", un préstamo de seis millones de dólares o de un millón 200000 libras esterlinas, equivalentes a seis millones de pesos españoles, decía lo siguiente:

Les concedo suficientes poderes para poder hipotecar las rentas, fondos y otras propiedades del Perú no importa cuántas obligaciones privilegiadas tengan además de llenar y completar cualquier otra condición que los dichos enviados puedan estipular (Temple Aguilar, 1973, p. 555).

El contrato era tan lesivo a los intereses de la nueva nación que el procurador inglés dictaminó que el préstamo era nulo por usurario, ya 
que obligaba al $6 \%$ de intereses sobre el capital nominal que el Perú pagaría durante 30 ańos.

San Martín y Monteagudo rompieron con Cochrane cuando este empezó a robar las medicinas del ejército, se quedó con todos los caudales pertenecientes al Estado y a particulares que habían sido depositados por orden de San Martín, primero en la Casa de la Moneda y luego llevados para mayor seguridad a uno de los barcos de la flota; además, el lord inglés trató de vender los barcos de la escuadra chilena que mandaba al nuevo gobierno peruano. La pasión dominante de Cochrane era la codicia, la misma que tendrían muchos otros personajes de nuestra historia.

Harto de intentos y hechos parecidos, Bolívar trató de cortar por lo sano: dictó la pena de muerte para los ladrones. El decreto de Bolívar decía lo siguiente:

[...] teniendo presente que una de las principales causas de los desastres en que se ha visto envuelta la república ha sido la escandalosa dilapidación de sus fondos por algunos funcionarios que han invertido en ellos

Que el único medio de extirpar radicalmente este desorden es dictar medidas fuertes y extraordinarias, he venido en decretar y decreto Artículo primero. Todo funcionario público a quien se le convenciere en juicio sumario de haber malversado o tomado para sí de los fondos públicos de diez pesos para arriba, queda sujeto a la pena capital.

Artículo segundo. Los jueces a quienes según la ley compete este juicio que en su caso no procedieren conforme a este decreto, serán condenados a la misma pena.

[...] El Imprímase publíquese y circúlese. Palacio dictatorial de Lima a doce de enero de 1824. (Sociedad Bolivariana de Venezuela, 1961, p. 283)

Apenas fue descubierto el guano de islas, el dinero logrado con la venta fue usado para la gran operación corrupta de la consolidación de la deuda interna por parte del gobierno de Echenique. Cuando el guano se constituyó en la principal entrada que sostenía al Estado 
peruano, el contrato Dreyfus se convirtió en el modelo inolvidable de corrupción en el siglo xIX. La corrupción forma parte esencial de nuestro ser nacional en todas las esferas y niveles de nuestra sociedad.

\section{Nuestra república}

Nacimos como una república coja. Tenía solamente una extremidad, la criolla, pero le faltaba la otra, la indígena, que servía solo como base para trabajar y pagar los mismos tributos coloniales a los cuales se denominó contribuciones indígenas. A pesar de que una parte de los indígenas luchó tanto en el bando realista como soldados como en el patriota, cual montoneros y guerrilleros, no le fue concedido ningún lugar en la república naciente. Desde 1823, las constituciones del siglo XIX ignoraron la existencia de los pueblos originarios. Además, como se sabe, la abolición de los curacazgos y cacicazgos los dejó sin guías ni líderes, que fueron sustituidos por amos, los latifundistas. No salieron ganando con la independencia, perdieron. Todo ello se agravó cuando los grupos ilustrados adoptaron las tesis del positivismo europeo que afirmaban el carácter primitivo y semisalvaje del $80 \%$ de la población peruana. En la primera república, la del siglo xIx, hasta la generación del novecientos, el positivismo coexistió con el garcilasismo. Se admiraba el pasado inca, pero se detestaba a los herederos de los incas degenerados por la ignorancia, el alcohol y la coca; y los jóvenes más progresistas de las élites peruanas participaban de una utopía arcaica garcilasiana que no cesaban de embellecer, al tiempo que de una visión racista de su época. La discriminación según la sangre blanca, india, judía o negra dividió a los habitantes del Virreinato en clases o castas superiores e inferiores. Esta división desapareció de la legalidad republicana, pero permaneció y, aún más, se ahondó durante los 200 años de república. De allí procede el racismo actual.

Decir indio rebelde era decir sangre, venganza colectiva, masacre de blancos. El temor a una gran sublevación india estuvo presente en sucesivas generaciones criollas hasta muy entrado el siglo xx. Ya era una república dividida con una gran brecha étnica en el medio. En realidad, como en la colonia, dos repúblicas: la de los indios continuaba 
dominada por señores latifundistas en vez de caciques y curacas. La de españoles se convirtió en república de criollos y señores de la tierra.

Al promediar el siglo xx esta división estalló al producirse lo que Matos Mar llamó el desborde popular. Un mar de gente bajó de los Andes a la costa y se asentó en los desiertos de Lima. La vieja ciudad virreinal quedó rodeada de millones de casuchas de estera que fueron convirtiéndose, por obra de sus propietarios a lo largo de ańos, en millones de casas de ladrillo construidas sin asistencia técnica, que cubrieron los desiertos y los cerros. El mundo neocolonial de la república criolla fue roto definitivamente. A la discriminación, a la división racial, sucedió el caos. ¿Es posible convertir este caos en un nuevo orden? ¿Es posible borrar las huellas de la ignorancia y el racismo?

\section{Conclusión}

En este artículo, he intentado mostrar las lejanas y, a la vez, presentes raíces de algunos de nuestros problemas. Tenemos todavía una matriz colonial que no hemos terminado de superar. La corrupción colonial goza de muy buena salud. El caos nos abruma y no sabemos ni tenemos diseñado un orden probable.

Ya no somos una colonia, pero todavía tenemos una mentalidad colonizada por los poderes globales. La república de indios se ha esfumado y se ha convertido en república de informales. La república de españoles continúa convertida en república de criollos, pero se le han añadido exitosos empresarios emergentes. Múltiples formas de discriminación han reemplazado a la discriminación racial. De la servidumbre colonial no se ha podido pasar a la ciudadanía democrática. El extenso virreinato ha reducido su área de dominio, ha cerrado sus fronteras y se ha superpoblado. Las minas de socavón han cerrado para ceder el espacio para enormes agujeros en los Andes. Ya no salen galeones que cargan tesoros hacia la península, sino grandes barcos muchas veces más grandes llevan containers cargados de millones de onzas de oro mucho más cuantiosas que el legendario rescate de Atahualpa. Todavía queda un país caótico que ordenar, una democracia que ampliar y una ciudadanía que construir. 


\section{Referencias}

Aguilar Meza, O. (2021). Francisco de Miranda, héroe de la Independencia ¿y masón? Asturias, España: Editorial Masónica.

Arana, M. (2020). Bolivar, libertador de América. Barcelona, España: Penguin Random House Grupo Editorial.

Arciniegas, G. (2005). Cuando América completó la tierra. Bogotá, Colombia: Villegas Editores.

Barrera Alarcón, V. (marzo 2015). El Taki Onqoy, la venganza de las huacas. Revista de Artes y Humanidades. 10, 18-27. Recuperado de https://www.researchgate.net/publication/273128262

Fernández Álvarez, M. (1999). Carlos V, el César y el hombre. Barcelona, España: Espasa- Calpe.

Fraga, R. (2016). El proyecto de la monarquía atemperada inca en el congreso de Tucumán. Buenos Aires, Argentina: Academia Nacional de Ciencias Morales y Políticas. Recuperado de https:// www.ancmyp.org.ar/user/files/Fraga-D-16.pdf

Guerra, F. (1988). Origen de las epidemias en la conquista de América. Quinto Centenario, 14, 43-51. Recuperado de https://revistas.ucm.es

Juan, J. \& de Ulloa, A. (Siglo XviII). Noticias secretas de América. (Tomo 1). Recuperado de http://www.cervantesvirtual.com/obra-visor/ noticias-secretas-de-america-tomo-i-siglo-xviii/html/

Rady, M. (2020). Los Habsburgo, soberanos del mundo. Barcelona, España: Taurus, Penguin Random House.

Temple Aguilar, E. (Ed.). (1973). Misión García del Río y Paroissien. Comisión Nacional del Sesquicentenario de la Independencia del Perú. Lima: p. 555. Recuperado de https://repombd.bnp. gob.pe/bnp/recursos/biblioteca1/HTML/Sesquicentenario/ misiones-peruanas-1820-1826-mision-garcia-del-rioparoissien-127524/664/ 
Van den Brule, A. (2016). El arma secreta de los españoles que causó carnicerías indiscriminadas en América. El Confidencial. Recuperado de https://www.elconfidencial.com/alma-corazonvida/2016-07-23/perros-virrey-hernan-cortes_1237619/ 